\title{
Glucose tolerance, ketose indices and body weight changes in heifers after calving
}

\author{
Sz. Fiedorowicz ${ }^{1,3}$, N. Strzalkowska², E. Bagnicka ${ }^{2}$, A. Jóźwik², \\ Z. Reklewski ${ }^{2}$ and J. Krzyżewski ${ }^{2}$ \\ ${ }^{1}$ Warsaw Agricultural University, Faculty of Animal Science \\ Ciszewskiego 8, 02-786 Warsaw, Poland \\ ${ }^{2}$ Institute of Genetics and Animal Breeding, Polish Academy of Sciences \\ Jastrzębiec, 05-552 Wólka Kosowska, Poland
}

\begin{abstract}
The aim of this study was to establish the relationship between parameters of the glucose tolerance test (GTT) of young heifers and their body weight after calving and at the peak of lactation, as well as the level of $\beta$-hydroxybutyric acid in blood serum at the peak of lactation. The GTT was conducted on 60 heifers HF at the age of 9-10 months. The animals were infused with $1 \mathrm{~g}$ glucose $/ \mathrm{kg} \mathrm{W}^{0.75}$ and 10 blood samples were taken at $6 \mathrm{~min}$ intervals. For $24 \mathrm{~h}$ before taking blood samples the animals received only water. Serum glucose concentrations and insulin activity were estimated. Correlation and regression between the area under the glucose concentration and insulin activity curves, the ratio of these areas (the glin index), maximum insulin activity, peak glucose concentration, glucose half-life, and body weight at the test, after calving and the peak of lactation, were calculated. The index "glin" seems to be the best parameter for estimation of body weight after calving and at the peak of lactation.
\end{abstract}

KEY WORDS: cow, glucose tolerance test, ketose, body weight

\section{INTRODUCTION}

Early prediction of dairy cattle milk traits on the basis of the relationship between the rate and pathway of energy metabolism of animals in early stages of life has been studied (Panicke et al., 2002; Sasaki et al., 2003). Little information on the relationship between the parameters of the glucose tolerance test (GTT) of young heifers and their body weight in the periparturient period and at the peak

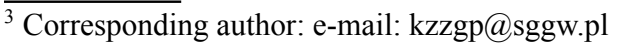


of lactation is available in the literature, however. The body weight of cows is related to the amount of consumed feed and the degree of its utilization for milk production (Van Arendonk, 1992). Feed consumption by high-yielding cows does not usually cover their requirement after calving, leading to ketosis. A sensitive indicator of this disturbance is the level of $\beta$-hydroxybutyric acid in blood serum.

The aim of this study was to establish the relationship between GTT parameters of young heifers and their body weight after calving and at the peak of lactation, as well as the level of $\beta$-hydroxybutyric acid in blood serum at the peak of lactation.

\section{MATERIAL AND METHODS}

The studies were conducted on 60 heifers HF, which were maintained in a herd with an average yield of $9,600 \mathrm{~kg}$ milk containing $4.32 \%$ fat and $3.44 \%$ protein. The heifers were kept in a loose barn and were fed diets composed of maize silage, grass silage and concentrate mixture with premix containing minerals and vitamins. The animals were fed according to INRA standards, in conformity with the TMR system, to obtain a daily gain of 750-800 g. The animals were weighed just before the GTT was conducted $(m t)$, after calving $(m c w)$, and at the peak of lactation $(m c 60)$.

The glucose tolerance test (GTT) was conducted at the age of 9-10 months according to Staufenbiel et al. (2000). Heifers were infused with $1 \mathrm{~g}$ glucose/ $\mathrm{kg} \mathrm{W}^{0.75}$ into the jugular vein. On the day of infusion the heifers received only water. The concentration of glucose was determined using the oxidase method (Alpha Diagnostics), insulin activity, using Insulin RIA Kits (Linco Research Inc., USA). In the statistical analysis, the following parameters were calculated: the areas under the insulin activity (ins) and glucose concentration $(g l u)$ curves, the ins/glu index (glin), maximum activity of insulin (imax), peak concentration of glucose (gmax), and glucose half-life $(h t)$. The blood samples were taken first just before infusion and then 9 times after infusion in 6 min intervals. The level of $\beta$-hydroxybutyric acid $(\mathrm{bhm})$ was determined in blood serum at the peak of lactation using RANBUT KITs (Randox).

The regression equation was calculated using the REG procedure, while Pearson correlations, using the CORR procedure of the SAS package.

\section{RESULTS AND DISCUSSION}

The highest negative correlations were between the glin index and $m t, m c w$ and $m c 60$ (Table 1). The correlations between ins and $m c t, m c w$ and $m c 60$ were positive and slightly lower. The negative correlations between glin, glu, and $h t$ 
and body weight may suggest that a faster glucose metabolism was connected with a higher live body gain. This was probably related to greater utilization of glucose by peripheral tissues.

The correlation coefficient between the level of bhm and mct was low and negative, while correlations between $b \mathrm{hm}$ and $\mathrm{mcw}$ and $m c 60$ were positive and low. It is likely that the low value of these correlations was determined by the relatively low level of $b h m$, which was in the physiological range.

Table 1. Correlation coefficients between selected GTT parameters and body weight of heifers

\begin{tabular}{lccc}
\hline Parameter & $M c t$ & $M c w$ & $m c 60$ \\
\hline glu & 0.021 & $-0.295^{* * *}$ & $-0.220^{* * *}$ \\
ins & $0.534^{* * *}$ & $0.209^{* * *}$ & $0.276^{* * *}$ \\
glin & $-0.575^{* * *}$ & $-0.369^{* * *}$ & $-0.494^{* * *}$ \\
ht & $-0.241^{* * *}$ & $-0.119^{* * *}$ & $-0.202^{* * *}$ \\
bhm & $-0.144^{* *}$ & $0.239^{* * *}$ & $0.147^{* * *}$ \\
gmax & $0.122^{* *}$ & $-0.204^{* * *}$ & $-0.125^{* *}$ \\
imax & $0.278^{* * *}$ & 0.079 & $0.168^{* * *}$ \\
\hline
\end{tabular}

$* \mathrm{P}<0.05, * * \mathrm{P}<0.01, * * * \mathrm{P}<0.001$

$m c t$ - body weight at the time of GTT, $m c w$ - body weight after calving, $m c 60$ - body weight at the peak of lactation $\left(60^{\text {th }}\right.$ day of lactation), $g l u$ - area under the curve of glucose concentration, ins - area under the curve of insulin activity, glin - index of gli/ins, ht - glucose half-life, bhm - level of $\beta$-hydroxybutyric acid at the peak of lactation, gmax - maximum concentration of glucose, imax - maximum activity of insulin

A regression equation was used to determine the value of changes between GTT parameters and the body weight of animals. The GTT parameters were independent variables, while live body weights were dependent variables (Tables 2 and 3).

On this basis, the body weight of cows in later periods of their life can be predicted with a high probability. The body weight of cows is related to the rate and pathway of energy metabolism, which influences milk yield and occurrence of ketosis.

Table 2. Regression of live body weights on the area under the curve of insulin activity

\begin{tabular}{lccc}
\hline$\hat{\mathrm{Y}}$ & \multicolumn{1}{c}{ Regression equation } & $\mathrm{R}^{2}$ & Xwp \\
\hline$m c t$ & $\hat{\mathrm{Y}}=195.7+0.01418 \mathrm{x}-3.39078 \mathrm{E}-7 \mathrm{x}^{2}$ & 0.4816 & 23633 \\
$m c w$ & $\hat{\mathrm{Y}}=443.0+0.01028 \mathrm{x}-2.78942 \mathrm{E}-7 \mathrm{x}^{2}$ & 0.1615 & 20560 \\
$m c 60$ & $\hat{\mathrm{Y}}=458.9+0.01103 \mathrm{x}-2.96033 \mathrm{E}-7 \mathrm{x}^{2}$ & 0.2653 & 22060 \\
\hline
\end{tabular}

$\hat{\mathrm{Y}}$ - value of traits, $\mathrm{R}^{2}$ - coefficient of determination, Xwp - value of X axis of parabola pick

Despite the moderately negative correlation between $g l u, m c w$, and $m c 60$, the regression coefficients were not significant. Thus, the glu parameter was useless as an indicator to predict the body weight of cows. 
The best GTT parameter for estimation of body weight after calving and at the peak of lactation seems to be the glin index. The highest coefficients of correlation were obtained between the glin index and live body weight in each investigated period.

Table 3. Regression of body weights on the glin index

\begin{tabular}{lcc}
\hline$\hat{\mathrm{Y}}$ & Regression equation & $\mathrm{R}^{2}$ \\
\hline$m c t$ & $\mathrm{Y}=350.9-53.60365 \mathrm{x}$ & 0.3495 \\
$m c w$ & $\mathrm{Y}=544.1-35.32113 \mathrm{x}$ & 0.1435 \\
$m c 60$ & $\mathrm{Y}=570.4-41.14224 \mathrm{x}$ & 0.2704 \\
\hline
\end{tabular}

see Table 2

It is difficult to compare our results with those obtained in other studies, because there is no information in the literature concerning the relationships between the GTT parameters of heifers and their body weight after the first calving. On the other hand, the results of some investigations indicate that there is significant correlation between GTT parameters and milk yield and its chemical composition (Sasaki et al., 2003). Moreover, a close correlation between the body weight of cows and their milk yield was shown (Van Arendonk, 1992). Because the existence of relationships between GTT parameters of heifers and body weights after calving was demonstrated in our study, we suppose that using the GTT, one could predict the milk yield of heifers with a high probability. This would enable preliminary selection for milk yield before insemination and accelerate genetic gain in milk cattle breeding.

\section{REFERENCES}

Panicke L., Fischer E., Staufenbiel R., Reklewski Z., 2002. Variation of parameters of the glucose tolerance test (GTT) in growing cattle. Anim. Sci. Pap. Rep. 20, 55-61

Sasaki O., Yamamoto N., Togashi K., Minezawa M., Ishii K., Takeda H., 2003. Use of plasma metabolite concentrations after glucose injection to predict the genetic ability of milk production in young calves. Jpn. Agr. Res. Quart. 37, 133-140

Staufenbiel R., Reinicke U., Panicke L., 2000. Glikosetoleranztest bei Kälbern und Kühen Methode, Einfluß des Lebensalters und Beziehung zur Milchleistung. Arbeitstagung DAN Polymorphismen beim Milchrind. Seebad Graal - Müritz, pp. 29-33

Van Arendonk J.A.M., 1992. Genetic relationships between feed intake, efficiency and production traits in growing bulls, growing heifers and lactating heifers. Proceedings of $43^{\text {rd }}$ Annual Meeting of EAAP, Madrid, G. VI, 1, 276-277 